\title{
Unilateral perivertebral fibrosis associated with lordosis, kyphosis and scoliosis (LKS) in farmed Chinook salmon in New Zealand
}

\author{
John S. Munday ${ }^{1, *}$, Matthew R. Perrott ${ }^{1}$, Jane E. Symonds ${ }^{2,5}$, Seumas P. Walker ${ }^{2,6}$, \\ Bailey Lovett ${ }^{3}$, Mark A. Preece ${ }^{4}$, Peter S. Davie ${ }^{1}$ \\ ${ }^{1}$ Institute of Veterinary, Animal and Biomedical Sciences, Massey University, Tennent Drive, Palmerston North 4442, New Zealand \\ ${ }^{2}$ National Institute of Water and Atmospheric Research, Bream Bay Aquaculture Park, Ruakaka 0116, New Zealand \\ ${ }^{3}$ Leigh Marine Laboratory, Department of Marine Science, University of Auckland, 160 Goat Island Road, Leigh 0985, New Zealand \\ ${ }^{4}$ New Zealand King Salmon, 43 Dublin Street, Picton 7220, New Zealand \\ ${ }^{5}$ Present address: Cawthron Institute, 98 Halifax St, Nelson 7010, New Zealand \\ ${ }^{6}$ Present address: Aqua Production Plus Ltd., 9 Panorama Drive, Nelson 7011, New Zealand
}

\begin{abstract}
Vertebral column lordosis, kyphosis and scoliosis (LKS) can result in downgrading of farmed Chinook salmon Oncorhynchus tshawytscha in New Zealand. No cause of LKS has been identified. Radiography and histology were used to quantify LKS and perivertebral fibrosis in 27 fish with LKS visible at harvest and 30 visually normal fish from 3 New Zealand farms. Radiographic LKS was present in all 27 fish with LKS and in 18 of 30 fish without visible LKS. Quantification of the radiographic severity revealed significantly higher radiographic severity scores in fish with visible LKS (mean $\pm \mathrm{SD}=5.89 \pm 2.41$ ) than in fish with no visible, but radiographic LKS $(1.44 \pm 0.86, \mathrm{p}<0.001)$. The most frequent histological finding was unilateral perivertebral fibrosis that often extended into the horizontal septum and adjacent myomeres resulting in separation or loss of myocytes. Fibrosis was visible in all fish with LKS and in 12 of 30 fish without visible LKS. Fibrosis scores were higher in fish with visible LKS $(3.32 \pm 1.71)$ than in fish without visible LKS $(0.35 \pm 0.57, \mathrm{p}<0.001)$. The radiographic LKS severity scores were significantly correlated to the fibrosis scores $\left(R^{2}=0.59 p<0.001\right)$ in the fish. Histology of other tissues revealed multifocal inflammation within muscle, peripheral connective tissues and myocardium which were considered most likely incidental in these fish. In this study, LKS was consistently and significantly associated with perivertebral fibrosis, suggesting that perivertebral fibrosis is an important process in the development of LKS. Further research to determine the cause of the fibrosis is required.
\end{abstract}

KEY WORDS: Oncorhynchus tshawytscha - Spinal curvature - Aquaculture - Histopathology · Inflammation $\cdot$ Pathogenesis $\cdot$ Salmonid

Resale or republication not permitted without written consent of the publisher

\section{INTRODUCTION}

Salmon farming is an important aquaculture industry in New Zealand, worth around NZ\$130 million ( US\$90 million) annually (www.salmon.org. nz). While Atlantic salmon Salmo salar is the predominant species farmed elsewhere in the world,
Chinook salmon Oncorhynchus tshawytscha is the only farmed salmonid in New Zealand. As the New Zealand salmon industry is the only one to exclusively farm Chinook salmon, it appears likely that disease conditions could be observed in the New Zealand salmon industry that are not observed elsewhere in the world. 
Spinal deformities were first recognized in farmed fish in the 1970s and are currently a significant problem in many aquaculture industries (Silverstone \& Hammell 2002, Boglione et al. 2013a, Cobcroft \& Battaglene 2013). In farmed Atlantic salmon, deformities have been detected by visible examination and palpation in around a quarter of fish at harvest and in up to $70 \%$ of fish by radiography (Fjelldal et al. 2012b). Spinal deformities have been reported to result in slower growth and reduced harvest weights (Hansen et al. 2010). Additionally, the presence of severe deformities can also reduce the value of the fish due to difficulties during processing and the presence of increased connective tissue in fillets from affected fish (Haugarvoll et al. 2010). Twenty different spinal deformity subtypes have been described in Atlantic salmon (Witten et al. 2009). In this species, vertebral compressions and fusions are reported most frequently and are suspected to be the result of altered vertebral bone development (Witten et al. 2005, 2006, Fjelldal et al. 2007). In contrast, vertical or horizontal curvature of the spine (lordosis, kyphosis, scoliosis: LKS) is rare in farmed Atlantic salmon (Boglione et al. 2013b). LKS can occur without underlying bone changes, and a neuromuscular rather than bone-related aetiology has been proposed (Witten et al. 2009). Currently, factors thought to influence the development of spinal deformities in farmed Atlantic salmon include water conditions such as temperature and currents, nutritional factors, mineral or vitamin deficiencies (especially phosphorus and vitamin $\mathrm{C}$ ), toxicities, genetics, trauma, vaccination, swim bladder dysfunction, weight at smoltification, growth rate of the fish and infectious agents (Silverstone \& Hammell 2002, Gil-Martens 2010, Boglione et al. 2013b). However, spinal deformity in Atlantic salmon appears multifactorial, and few factors have reliably reproduced deformity in laboratory conditions (Boglione et al. 2013b).

In contrast to farmed Atlantic salmon, LKS is the most common spinal abnormality of farmed Chinook salmon in New Zealand, and no cause for this condition has been identified to date (M. R. Perrott et al. unpubl. data). The prevalence of LKS varies between farms and even among individual pens within the same farm. However, some degree of LKS can be detected by radiography in up to $40 \%$ of Chinook salmon at harvest, suggesting that this condition could impact farm profitability (M. R. Perrott et al. unpubl. data). Chinook salmon typically develop LKS late in the production cycle. While LKS has also been reported in other farmed fish species, especially European seabass Dicentrarchus labrax, gilthead seabream Sparus aurata and Atlantic cod Gadus morhua (Chatain 1994, Andrades et al. 1996, Boglione et al. 2013b), LKS in these fish species appears to be most common early in life. While initial evidence suggested that LKS in these fish may be due to underinflation of the swim bladder (Chatain 1994), this finding has not been observed in most subsequent studies (Andrades et al. 1996, Boglione et al. 2013b). Idiopathic scoliosis is one of the most common causes of spinal curvature in humans (Gorman et al. 2012). As is seen in Chinook salmon with LKS, the severity of curvature tends to increase with age (Gorman et al. 2012). The aim of the present study was to investigate the microscopic changes present in fish with LKS. Determining the histology associated with LKS in salmon may suggest likely causal factors and could allow strategies to be developed to reduce the incidence of LKS in farmed Chinook salmon.

\section{MATERIALS AND METHODS}

\section{Study 1: Histopathology of vertebrae and perivertebral tissues}

Chinook salmon were collected at harvest from 3 different marine farms that were in widely spread geographic locations in New Zealand. Fish were collected from Farm A in July 2015, Farm B in October 2015 and Farm C in March 2015. Fish from each farm received a commercially prepared diet from 1 of 2 different feed companies. Salmon were harvested at 2 to 3 yr of age when they reached a target weight, according to standard practice on each of the farms. At harvest, the fish were assessed visually and classified as either having or not having visible LKS. Whole fish were packed in ice and shipped so that all samples were collected within $24 \mathrm{~h}$ of harvest. The prevalence of LKS within the farms was not noted at the time of sampling, so no comparison of the rate of LKS in each farm was possible as part of this study.

All fish were weighed and the fork length measured. A radiograph was taken of the whole spinal column of each fish with a Philips Bucky Diagnostics Ceiling System (Royal Philips) and a Canon CXDI$50 \mathrm{G}$ sensor $80 \mathrm{~cm}$ from source, set at $60 \mathrm{kV}, 3.2 \mathrm{mAs}$. Digital images were reviewed on Clearcanvass vetstation (Synaptive Medical) or as .jpg files using Adobe Photoshop CS6 (Adobe Systems). Radiographs were examined for abnormalities in each of the 4 regions of the vertebral column that have previously been defined for Atlantic salmon (Kacem et al. 

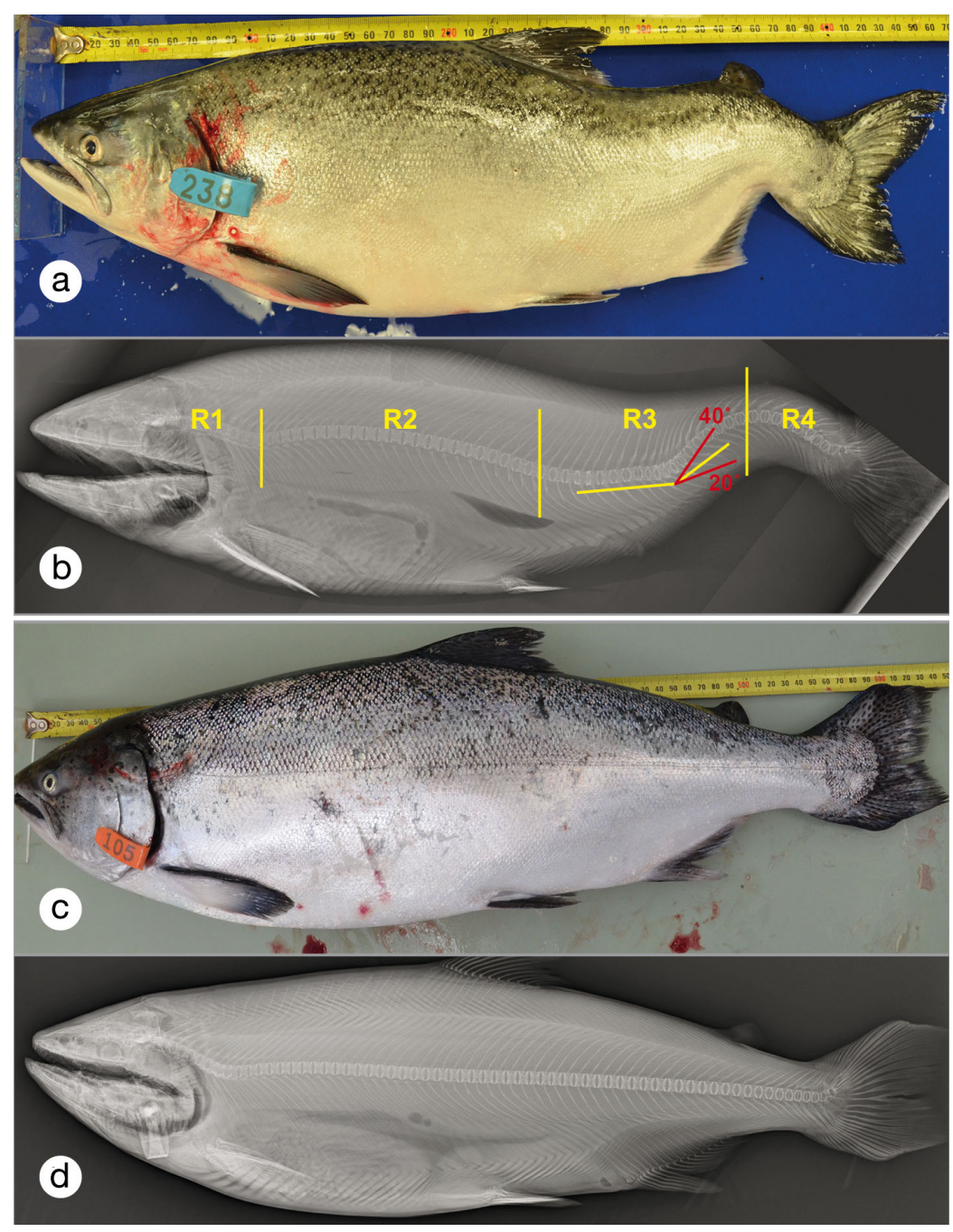

Fig. 1. (a) Photograph and (b) radiograph of a Chinook salmon Oncorhynchus tshawytscha with visible lordosis, kyphosis and scoliosis (LKS). Spinal regions 1 to 4 (R1-R4) are indicated, and severity 2 lordosis (between 20 and $40^{\circ}$ angle of curvature; see 'Materials and methods') in region 3 is illustrated. (c) Photograph and (d) radiograph of a fish with no visible, but radiographic evidence of LKS (lordosis) in the cranial region

1998). Region 1 consisted of vertebra 1 to vertebra 8 , region 2: vertebra 9 to 31 , region 3: vertebra 32 to 50 and region 4: vertebra 51 to $\sim 63$ (Fig. 1). Not all fish have the same number of vertebrae, and this variation is included in region 4 . The radiographs were evaluated for 4 abnormality types including LKS (types 14,15,16), fusions (types $6,7,8$ ), compressions (types 1, 2, 3, 4, 5) and vertical shifts (type 17) (Witten et al. 2009).

To determine the severity of the LKS, the angle of the curvature of the spine was assessed by protractor on the monitor. Severity 1 was when the angle of curvature was less than $20^{\circ}$, severity 2 was 20 to $40^{\circ}$, and severity 3 was $>40^{\circ}$. The total radiographic LKS severity score for each fish was derived by adding the radiographic LKS severity scores from all 4 regions of the spine.

For histology, a 3-vertebrae-long sample of the spine and adjacent soft tissue was taken from the middle of each of the 4 described regions (Kacem et al. 1998). While it cannot be confirmed that the identical vertebrae were taken from each fish, the samples were taken using clear landmarks on the fish so that similar vertebrae were sampled from each fish. Samples of vertebrae and perivertebral muscle $(45-100 \mathrm{~g})$ were fixed in 10\% neutral buffered formalin (NBF) which was changed after $1 \mathrm{wk}$. For decalcification, formic acid (FA) was added to the $10 \%$ NBF to make a $5 \%$ FA solution. After $72 \mathrm{~h}$, this solution was replaced with a $10 \%$ FA-NBF solution and the tissue was decalcified for an additional $72 \mathrm{~h}$. Tissue was cut up to present a transverse section through the midcentrum and another through the intervertebral space. Cut surfaces in cassettes were further decalcified in a $5 \%$ FA-NBF solution for $48 \mathrm{~h}$, rinsed in running water for $1 \mathrm{~h}$ and processed. Samples were processed for histology by graded dehydration in ethanol, clearing in xylene and then embedding in paraffin. Sections were cut at $5 \mu \mathrm{m}$ and mounted on superfrost plus slides (Menzel-Gläser). After baking sections onto slides for $30 \mathrm{~min}$ at $60^{\circ} \mathrm{C}$, tissues were dewaxed in xylene, rehydrated in graded alcohol and transitioned to water for staining. A progressive haematoxylin and eosin (H\&E) method was performed on all slides while a periodic acid-Schiff reaction and Masson's trichrome stain were performed on selected sections using standard protocols on an autostainer XL staining platform (Leica Biosystems).

For each section, any abnormality was recorded. In addition, each section was assigned a histology score that quantified the extent of the fibrosis visible on the slide (Table 1). As 2 transverse sections were evaluated for each region, an average of both sections was used as the histology score for each region. The total histology score for each fish was derived by adding the histology scores from the 4 regions of the spine. 
Table 1. Criteria used to assign a histology score for each section of vertebra examined in Chinook salmon Oncorhynchus tshawytscha

$$
\begin{array}{ll}
\text { Score } & \text { Histological description } \\
\hline 0 & \text { No histological abnormalities detected } \\
1 & \begin{array}{l}
\text { Presence of perivertebral fibrosis that is either } \\
\text { dorsal or ventral to the horizontal septum with } \\
\text { minimal extension into adjacent muscle }
\end{array} \\
2 & \begin{array}{l}
\text { Fibrosis in over } 75 \% \text { of the perivertebral tissue } \\
\text { either dorsally or ventrally to the horizontal }
\end{array} \\
& \text { septum or in 20-50\% of the perivertebral tissue } \\
& \text { unilaterally. Moderate extension into adjacent } \\
& \text { muscle } \\
& \text { Fibrosis present within over 50\% of the peri- } \\
& \text { vertebral tissue unilaterally or marked fibrosis } \\
& \text { resulting in significant expansion of the horizon- } \\
\text { tal septum and surrounding perivertebral } \\
\text { tissues. Frequent extension into the periverte- } \\
\text { bral muscle }
\end{array}
$$

All evaluations were performed by the same pathologist who was blinded to the group of origin of each slide.

Differences between fish with and without visible LKS, and differences between fish with visible LKS, fish with no visible but radiographic evidence of LKS, and fish with neither visible nor radiographic LKS were analysed using ANOVA, and the correlation between radiology and histology scores was investigated using linear regression. All statistical analyses were performed using IBM SPSS statistics Version 22 with $\mathrm{p}<0.05$ considered significant.

\section{Study 2: Histopathology of non-vertebral tissues from fish with LKS}

Fish for Study 2 were taken independently of the fish in Study 1. All were from Farm A and were harvested in January 2015. At harvest, the fish were classified into fish with visible LKS $(\mathrm{n}=16)$ and fish with no visible evidence of LKS $(\mathrm{n}=14)$. As before, fish were shipped on ice and samples were taken within $24 \mathrm{~h}$ of death. Samples of skeletal muscle from each of the 4 vertebral regions, brain, gill, heart, spleen, liver, kidney, pancreas, stomach, ovary and pyloric caeca were taken, fixed in formalin and routinely processed for histological examination as described above. As before, each section was assessed by 1 pathologist who was blinded to the group of origin of the tissues. Samples of vertebrae were not available from these fish, and no sections of vertebrae or perivertebral tissues were examined.
Table 2. Summary of Chinook salmon Oncorhynchus tshawytscha included in the study. Fish were subdivided at harvest into those with visible lordosis, kyphosis and scoliosis (LKS) and those without. Data are presented as means (SD)

\begin{tabular}{|lccc|}
\hline Group & $\mathrm{n}$ & Weight $(\mathrm{g})$ & Length (mm) \\
\hline Farm A & & & \\
LKS & 12 & $2467(1021)$ & $492(81)$ \\
No LKS & 17 & $3632(696)$ & $594(43)$ \\
Farm B & & & \\
LKS & 9 & $1210(96)$ & $382(108)$ \\
No LKS & 8 & $3325(378)$ & $594(26)$ \\
Farm C & & & \\
LKS & 6 & $2591(332)$ & $546(37)$ \\
No LKS & 5 & $3166(210)$ & $618(17)$ \\
\hline
\end{tabular}

\section{RESULTS}

\section{Study 1}

This study comprised 57 fish including 27 fish that had visible LKS at harvest and 30 fish without visible LKS. Fish without visible LKS were significantly heavier and longer than fish with visible LKS from all 3 farms (Table 2, $\mathrm{p}<0.01$ ).

Radiography confirmed the presence of LKS in all 27 fish with visible LKS. However, radiographic evidence of LKS was also detected in 18 of 30 fish that did not have visible LKS at harvest (Table 3). Radiographic severity scores were significantly higher in fish with visible LKS $(5.89 \pm 2.41$, mean \pm SD) than they were in fish with no visible, but radiographic evidence of LKS $(1.44 \pm 0.86, p<0.001)$. In fish with visible LKS, we found no significant differences in the radiographic scores of LKS between the 4 vertebral regions in fish from Farm A (Table 4). However, radiographic scores were significantly higher in regions 2, 3 and 4 than in region 1 in fish from Farm $\mathrm{B}$ and in regions 3 and 4 than in region 1 in Farm C. Radiographic lesions of LKS were often accompanied by vertical shifts and compressions within the spine. However, fusions were only identified in 8 fish.

The most frequent histological change observed was perivertebral fibrosis, which was present in all 27 fish with visible LKS at harvest. In addition, fibrosis was visible in 7 of 18 fish that had radiographic, but no visible evidence of LKS, and in 5 of 12 fish that had neither visible nor radiographic evidence of LKS (Table 3). The fibrosis was typically unilateral and present lateral to the connective tissue that surrounds the vertebrae (Fig. 2). The most prominent fibrosis was often around the insertion of the horizontal septum that separates the epaxial 
Table 3. Summary of visual and radiographic LKS assessment of Chinook salmon Oncorhynchus tshawytscha. The radiographic (Rad.) score is a quantitative assessment of radiographic severity of LKS while the histology (Histo.) score is the severity of perivertebral fibrosis observed in the fish (see Table 1). The radiographic and histology scores are presented as means $\pm \mathrm{SD}$

\begin{tabular}{|c|c|c|c|c|c|c|c|c|c|}
\hline & \multicolumn{3}{|c|}{ None -} & \multicolumn{3}{|c|}{$\begin{array}{l}\text { LKS evidence observed - } \\
\text { Radiographic only }\end{array}$} & \multirow[b]{2}{*}{$\mathrm{n}$} & \multirow{2}{*}{$\begin{array}{l}\text { Visib } \\
\text { Rad. score }\end{array}$} & \multirow{2}{*}{ Histo. score } \\
\hline & $\mathrm{n}$ & Rad. score & Histo. score & $\mathrm{n}$ & Rad. score & Histo. score & & & \\
\hline All fish & 12 & 0 & $0.28 \pm 0.39$ & 18 & $1.44 \pm 0.86$ & $0.39 \pm 0.67$ & 27 & $5.89 \pm 2.41$ & $3.32 \pm 1.71$ \\
\hline With fibrosis & 5 & 0 & $0.67 \pm 0.31$ & 7 & $1.43 \pm 0.79$ & $1.01 \pm 0.74$ & 27 & $5.89 \pm 2.41$ & $3.32 \pm 1.71$ \\
\hline Without fibrosis & 7 & 0 & 0 & 11 & $1.45 \pm 0.93$ & 0 & 0 & - & - \\
\hline
\end{tabular}

from the hypaxial muscles (Fig. 3). Fibrosis was also often visible forming a cuff surrounding the perivertebral connective tissue. Interestingly, the fibrosis remained lateral to the perivertebral connective tissue, and increased fibrosis was not visible immediately adjacent to the vertebral bone (Fig. 4). Fibrosis was often also present expanding the horizontal septum and extending into the myosepta of both epaxial and hypaxial muscles. In mild cases, this appeared as separation of individual myocytes by increased fibrous tissue. However, in more severe cases, thick bands of fibrosis were present dissecting the myomeres with myocytes that were surrounded by the fibrosis, appearing small and brightly eosinophilic (Fig. 5). This change was more

Table 4. Summary of the radiographic and histologic findings in 27 Chinook salmon Oncorhynchus tshawytscha with visible LKS at harvest and 30 fish that were visibly unaffected. For fish with LKS, spinal regions with the same superscript letter did not show significant differences in the mean radiographic and histology scores $(p<0.05)$. Regions were not compared between farms. Data are presented as means (SD)

\begin{tabular}{|c|c|c|c|c|}
\hline \multirow{2}{*}{$\begin{array}{l}\text { Spinal } \\
\text { region }\end{array}$} & \multicolumn{2}{|c|}{ Radiology score } & \multicolumn{2}{|c|}{ — Histology score } \\
\hline & No visible LKS & Visible LKS & No visible LKS & Visible LKS \\
\hline \multicolumn{5}{|l|}{ Farm A } \\
\hline Region 1 & $0.06(0.24)$ & $0.83(0.94)^{\mathrm{a}}$ & $0.08(0.19)$ & $0.19(0.39)^{\mathrm{a}}$ \\
\hline Region 2 & $0.76(0.56)$ & $1.08(1.08)^{\mathrm{a}}$ & $0.12(0.35)$ & $0.39(0.39)^{\mathrm{a}}$ \\
\hline Region 3 & $0.23(0.44)$ & $1.83(1.19)^{\mathrm{a}}$ & $0.03(0.10)$ & $1.15(0.71)^{\mathrm{b}}$ \\
\hline Region 4 & $0(0)$ & $1.67(1.30)^{\mathrm{a}}$ & $0.06(0.18)$ & $1.15(1.09)^{\mathrm{b}}$ \\
\hline Total & $1.06(0.97)$ & $5.42(3.03)$ & $0.29(0.55)$ & $2.89(0.55)$ \\
\hline \multicolumn{5}{|l|}{ Farm B } \\
\hline Region 1 & $0.25(0.46)$ & $0.33(0.50)^{\mathrm{a}}$ & $0.06(0.17)$ & $0.33(0.35)^{\mathrm{a}}$ \\
\hline Region 2 & $0.50(0.76)$ & $1.67(1.22)^{\mathrm{b}}$ & $0.06(0.18)$ & $0.61(0.55)^{\mathrm{a}}$ \\
\hline Region 3 & $0(0)$ & $2.44(0.88)^{\mathrm{b}}$ & $0(0)$ & $0.89(0.74)^{\mathrm{a}}$ \\
\hline Region 4 & $0(0)$ & $2.44(0.88)^{\mathrm{b}}$ & $0.06(0.18)$ & $0.94(1.04)^{\mathrm{a}}$ \\
\hline Total & $0.75(1.16)$ & $6.78(2.05)$ & $0.19(0.26)$ & $2.78(1.39)$ \\
\hline \multicolumn{5}{|l|}{ Farm C } \\
\hline Region 1 & $0.20(0.45)$ & $0.33(0.52)^{\mathrm{a}}$ & $0(0)$ & $0.17(0.41)^{\mathrm{a}}$ \\
\hline Region 2 & $0(0)$ & $1.33(1.03)^{\mathrm{ab}}$ & $0.2(0.45)$ & $0.83(0.98)^{\mathrm{ab}}$ \\
\hline Region 3 & $0(0)$ & $2.00(0.63)^{b}$ & $0(0)$ & $1.67(1.21)^{\mathrm{bc}}$ \\
\hline Region 4 & $0.20(0.45)$ & $1.83(0.98)^{b}$ & $0.60(0.55)$ & $2.33(0.82)^{\mathrm{c}}$ \\
\hline Total & $0.40(0.55)$ & 5.5 (1.05) & $0.80(0.84)$ & $5.00(1.79)$ \\
\hline
\end{tabular}

consistent with myocyte atrophy than necrosis. In a small proportion of fish, the fibrosis was bilateral; however, it was invariably more severe on one side than the other. Rarely, in cases with severe fibrosis, the fibrosis was visible, extending within the connective tissue below the vertebral column to the opposite side of the fish. Likewise, the fibrosis was rarely of equal severity in the ventral and dorsal aspects of the perivertebral tissues and muscle. Peripheral nerves within the perivertebral connective tissue were often surrounded by fibrosis; however, the fibrosis did not appear to extend through the epineurium. Fibrosis was not visible within the meninges surrounding the spinal cord. As expected, the fibrosis stained green with Masson's trichrome.

Small numbers of mononuclear cells, interpreted as macrophages and lymphocytes, were typically scattered within the areas of fibrosis (Fig. 6). However, significant populations of granulocytes were also visible in around $5 \%$ of fish with fibrosis. These cells tended to be present as foci of inflammation that were adjacent to the areas of fibrosis. These cells were interpreted to represent a more acute inflammatory response.

The perivertebral connective tissues and the connective tissue of the horizontal septum in 2 fish with LKS were markedly expanded by loosely arranged fibroblasts that were separated by large quantities of pale basophilic amorphous material (Fig. 7). This material did not stain with periodic acid-Schiff and could not be definitively identified. Small numbers of granulocytes were visible associated with this change in both fish. In both fish, the amorphous material was only present unilaterally and only within sections of region 4 . 


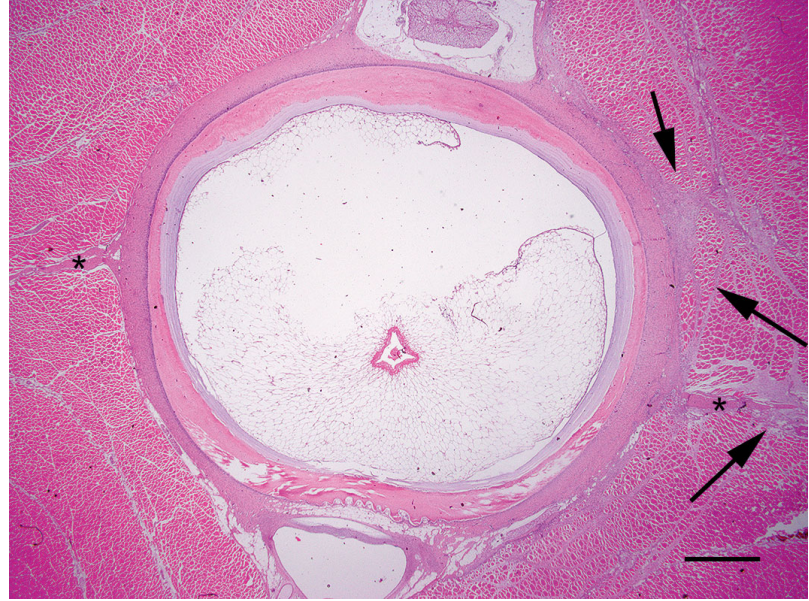

Fig. 2. Photomicrograph of a vertebra and perivertebral tissues from region 3 in a Chinook salmon Oncorhynchus tshawytscha with LKS. Note fibrosis adjacent to the connective tissue surrounding the intervertebral disc on the right (arrows). No fibrosis is visible on the left. Fibrosis within over half of the perivertebral tissue and the extension into the adjacent muscle resulted in a histological severity score of 3 for this section. Asterisks indicate horizontal septa. H\&E stain; scale bar $=750 \mu \mathrm{m}$

All fish that had visible LKS had histological evidence of perivertebral fibrosis or inflammation. Within the 18 fish that had no visible but radiographic evidence of LKS, histological lesions were visible in 7 fish. Within the 12 fish that had neither visible nor radiographic evidence of LKS, 5 fish had histological lesions.

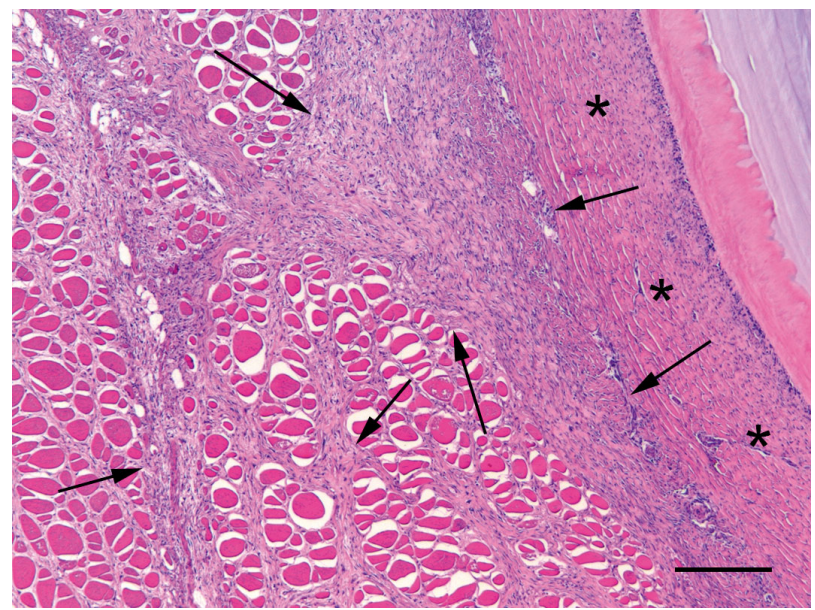

Fig. 4. Photomicrograph of perivertebral tissues from region 4 in a Chinook salmon Oncorhynchus tshawytscha with LKS. Fibrosis is visible adjacent to the connective tissue surrounding the intervertebral disc $(*)$. The connective tissue extends into adjacent muscle (arrows), causing separation of the myomeres. Individual myofibres are surrounded by a clear space, consistent with shrinkage of the myofibres caused by processing for histology. H\&E stain; scale bar = $200 \mu \mathrm{m}$

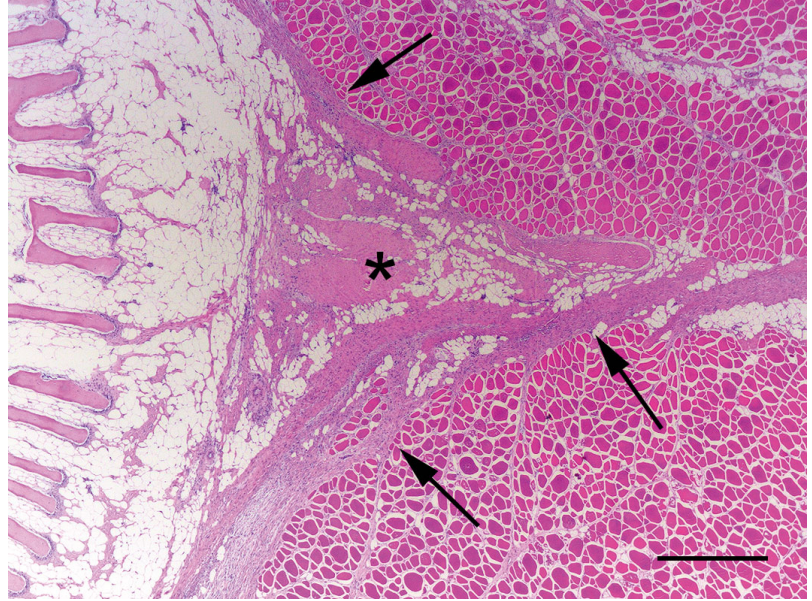

Fig. 3. Photomicrograph of a vertebra and perivertebral tissues from region 3 in a Chinook salmon Oncorhynchus tshawytscha with LKS. Fibrosis (arrows) is visible, expanding and surrounding the horizontal septum (*). Vertebral bone is visible on the left. Note that the fibrosis does not involve the periosteum of the bone. H\&E stain; scale bar $=400 \mu \mathrm{m}$

The total histology scores were significantly higher in fish with visible LKS $(3.32 \pm 1.71)$ than they were in fish with no visibly detectible LKS $(0.35 \pm 0.57, \mathrm{p}<$ 0.001). Significant differences in the total histology score were also present between fish that had visible LKS $(3.32 \pm 1.71)$ and fish that had no visible but radiographic evidence of LKS $(0.39 \pm 0.67, \mathrm{p}<0.001)$ and fish that had neither visible nor radiographic evi-

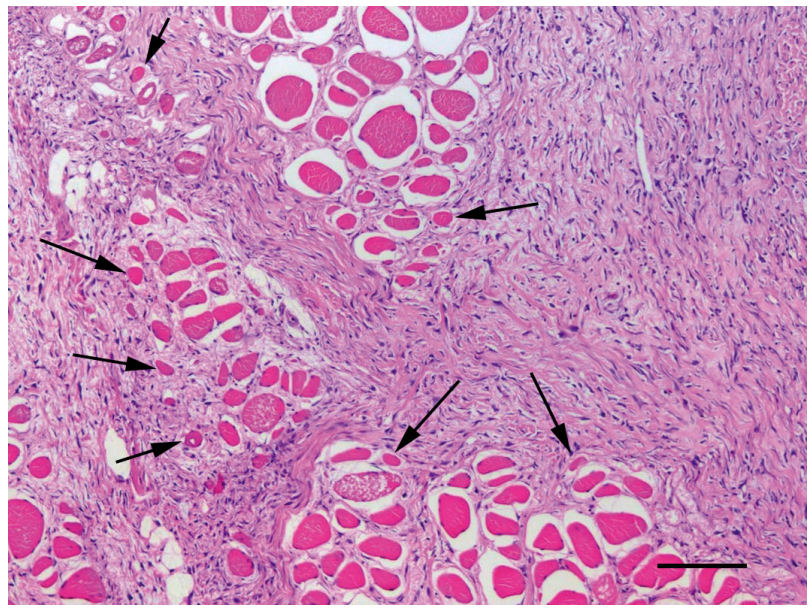

Fig. 5. Photomicrograph of perivertebral tissues from region 4 in a Chinook salmon Oncorhynchus tshawytscha with LKS. Note the marked expansion of the myosepta by large quantities of fibrous tissue. Fibrosis is also visible separating individual myocytes, and some myocytes are shrunken and eosinophilic (arrows). Individual myofibres are surrounded by a clear space, consistent with shrinkage of the myofibres caused by processing for histology. No evidence of necrosis of the muscle is visible. H\&E stain; scale bar $=50 \mu \mathrm{m}$ 


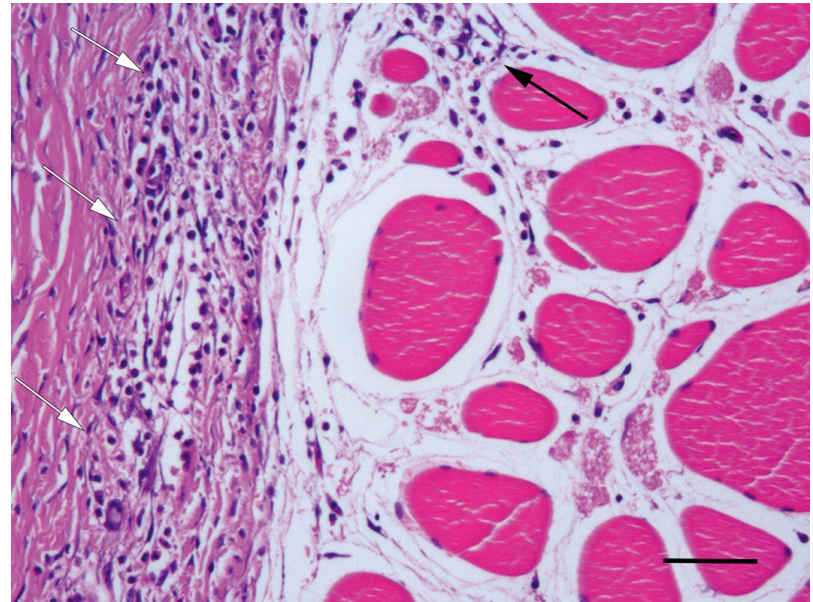

Fig. 6. Photomicrograph of perivertebral tissues from region 3 in a Chinook salmon Oncorhynchus tshawytscha with LKS. Small numbers of predominantly mononuclear inflammatory cells are scattered in the areas of fibrosis (white arrows). Inflammatory cells are also visible within the connective tissue surrounding myocytes (black arrow). H\&E stain; scale bar $=20 \mu \mathrm{m}$

dence of LKS $(0.28 \pm 0.39, p<0.001$; Table 5). In fish with visible LKS, significantly higher histology scores were seen in regions 3 and 4 than in regions 1 and 2 in fish from Farm A. In fish from Farm C, the histology score was higher in region 4 than in regions 1 and 2 , with region 3 having a significantly higher histology score than region 1 . In contrast, no significant differences in histology scores were observed between the regions in fish from Farm B. Overall, the histology score was significantly correlated to the radiographic LKS score $\left(\mathrm{R}^{2}=0.59, \mathrm{p}<0.001\right)$.

An additional histological lesion that was observed in a minority of fish was the presence of small numbers of inflammatory cells within the walls of perivertebral blood vessels. These cells did not appear to be associated with degeneration of the blood vessel, suggesting that they could be migrating inflammatory cells rather than evidence of vasculitis. Inflammatory cells were most often adjacent to areas of inflammation or fibrosis within the connective tissue, and cells

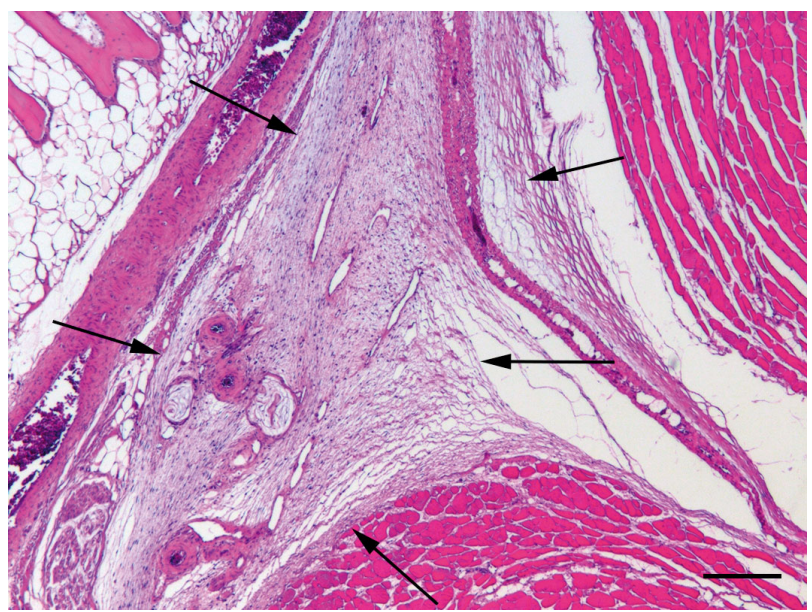

Fig. 7. Photomicrograph of perivertebral tissues from region 4 in a Chinook salmon Oncorhynchus tshawytscha with LKS. In a small proportion of fish, the horizontal septum was expanded by increased quantities of loose connective tissue and pale basophilic material (arrows) that was interpreted to potentially be evidence of a more acute inflammatory reaction. H\&E stain; scale bar $=200 \mu \mathrm{m}$

were not visible within blood vessels of fish that did not have perivertebral lesions. Histological examination of sections of vertebrae revealed few changes within the bone. However, the presence of increased cells within the periosteum adjacent to areas of fibrosis suggested the possibility that the fibrosis could result in some bone remodelling. There was no histological evidence of mineral loss, degeneration or inflammation of the vertebral bone. No significant lesions were observed within sections of the spinal cord.

\section{Study 2}

Examination of sections of white muscle revealed fibrosis in 7 of 16 (44\%) fish with LKS, but in none of the 14 fish without visible LKS. The fibrosis was only visible in sections of muscle from regions 3 or 4 and was always present extending to the deep margins of the muscle. This fibrosis was interpreted to represent

Table 5. Summary of histology scores that quantified the fibrosis present within the perivertebral tissues in Chinook salmon Oncorhynchus tshawytscha. Data are presented as mean (SD). For each region, values with a different superscript letter are significantly different $(\mathrm{p}<0.05)$. LKS: lordosis, kyphosis and scoliosis

\begin{tabular}{|lcccccc|}
\hline \multirow{2}{*}{$\begin{array}{l}\text { LKS evidence } \\
\text { observed }\end{array}$} & $\mathrm{n}$ & \multicolumn{4}{c}{ Spinal region } & \multicolumn{2}{c|}{ Total } \\
\cline { 3 - 6 } & & Region 1 & Region 2 & Region 3 & Region 4 & fibrosis \\
\hline None & 12 & $0(0)^{\mathrm{a}}$ & $0.04(0.14)^{\mathrm{a}}$ & $0.03(0.10)^{\mathrm{a}}$ & $0.21(0.40)^{\mathrm{a}}$ & $0.28(0.39)^{\mathrm{a}}$ \\
Radiology only & 18 & $0.12(0.21)^{\mathrm{ab}}$ & $0.17(0.40)^{\mathrm{a}}$ & $0.01(0.06)^{\mathrm{a}}$ & $0.11(0.28)^{\mathrm{a}}$ & $0.39(0.67)^{\mathrm{a}}$ \\
Visible & 27 & $0.23(0.37)^{\mathrm{b}}$ & $0.56(0.61)^{\mathrm{b}}$ & $1.18(0.86)^{\mathrm{b}}$ & $1.34(1.12)^{\mathrm{b}}$ & $3.32(1.71)^{\mathrm{b}}$ \\
\hline
\end{tabular}


an extension of the perivertebral fibrosis that had been observed in fish with LKS in Study 1. Small foci of inflammation were scattered in the red muscle, in the connective tissue between red and white muscle, or within the myocardium in 16 of $30(53 \%)$ of the examined fish (Fig. 8). However, no fibrosis was visibly associated with these foci and, as they were visible within 7 of 16 (44\%) of fish without LKS and 9 of $14(64 \%)$ of fish without visible LKS, these foci were considered to be an incidental finding. No other lesions were observed in sections of the other tissues taken from these fish.

\section{DISCUSSION}

Farmed Chinook salmon with LKS had significantly more fibrosis within the connective tissue and muscle adjacent to the vertebral column than fish without LKS. Furthermore, the extent of the fibrosis was significantly correlated with the radiographic LKS severity. These results therefore show that perivertebral fibrosis is associated with LKS in farmed Chinook salmon in New Zealand.

LKS is characterised by horizontal or vertical curvature of the spine. The association between fibrosis and LKS suggests that this curvature could develop as a result of the perivertebral fibrosis. Fibrosis is commonly referred to as 'scar tissue' and can lead to contraction and reduced flexibility in a tissue (Kumar et al. 2010). As the fibrosis was almost always unilateral and was typically more severe in either the dorsal or ventral tissues, it appears possible that the fibrosis could cause LKS. In the present study, the severity of the fibrosis was correlated to the radiographic severity of the LKS, suggesting that a greater degree of fibrosis results in more contraction, and therefore higher severity of LKS. While defects in vertebral bone development are hypothesized to cause most spinal deformities in Atlantic salmon (Fjelldal et al. 2012b, Boglione et al. 2013b), the possibility that perivertebral inflammation and fibrosis could cause spinal curvature in Atlantic salmon has been previously suggested (Kvellestad et al. 2000). Additionally, the possibility that LKS in Atlantic salmon has a neuromuscular rather than a bone aetiology has also previously been hypothesized (Witten et al. 2009). If perivertebral fibrosis is the cause of the LKS in Chinook salmon, this would suggest that LKS in Chinook salmon is similarly not a bone disorder, and would support the hypothesis that LKS in fish can have a neuromuscular origin.

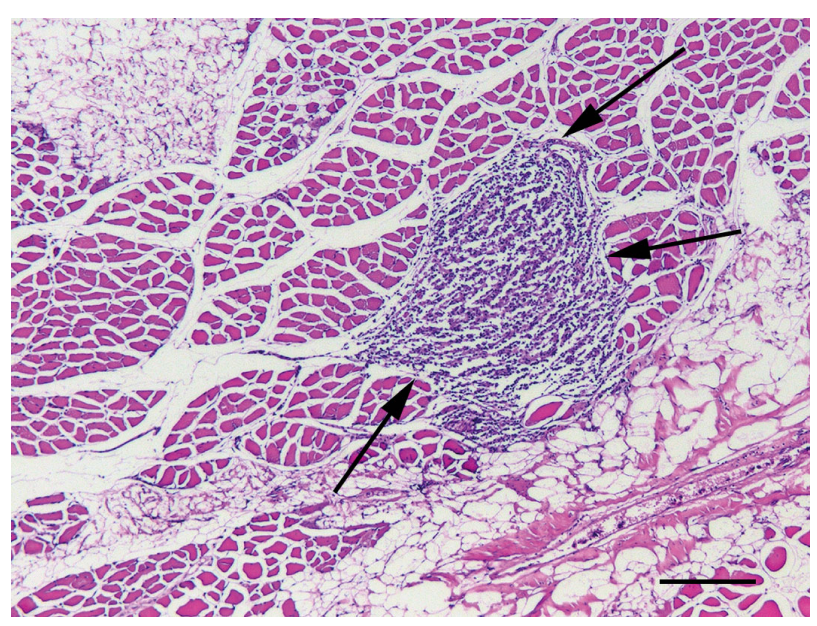

Fig. 8. Photomicrograph of red muscle close to the skin of a Chinook salmon Oncorhynchus tshawytscha. This fish had neither visible nor radiographic evidence of LKS. A focus of inflammation is visible within the connective tissue separating bundles of skeletal muscle (arrows). Individual skeletal muscle fibres are shrunken and are surrounded by a clear space, but this is considered an artefact caused by tissue processing rather than any muscle pathology. H\&E stain; scale bar $=0.2 \mathrm{~mm}$

In the present study, 11 fish in Study 1 had radiographic evidence of mild LKS without any histological evidence of fibrosis. The failure to identify fibrosis in these fish could suggest that fibrosis is not the cause of LKS. However, as only a small proportion of the perivertebral tissues from each fish was examined histologically, it is possible that these fish had fibrosis, but that this was missed during sampling. Likewise, 9 of the fish in Study 2 did not have histologically visible LKS. However, perivertebral tissues were not sampled from these fish and it is possible that these fish had perivertebral fibrosis, but this fibrosis did not extend laterally into the muscles sufficiently to be visible in the muscle samples taken. In the future, it would be interesting to serially examine the entire vertebral column and perivertebral tissues of fish with mild LKS. If it is confirmed that LKS can be present without fibrosis, this would be significant evidence that fibrosis is not the cause of the LKS in these fish.

The results of this study also raise the possibility that LKS could develop as a primary process and that changes to the perivertebral tissues are induced as a consequence of the spinal curvature. While examination did not reveal any other primary cause of LKS, it remains possible that another factor caused LKS which then caused perivertebral fibrosis in affected fish. However, perivertebral fibrosis was visible in 5 fish that had no radiographic evidence of LKS. 
Therefore, at least in these fish, it appears highly unlikely that the fibrosis developed secondary to local changes induced by LKS. Instead it seems more likely that these fish had mild or early disease in which the perivertebral fibrosis had not significantly affected the normal position of the spine. While additional research is required to confirm the progression of the changes, the results of the present experiment are more consistent with the fibrosis causing the LKS rather than the fibrosis developing due to LKS.

Fibrosis is considered the final reparative stage of a chronic inflammatory reaction (Kumar et al. 2010). Evidence supporting the presence of an inflammatory reaction in fish with LKS includes the variable numbers of inflammatory cells admixed within the fibroblasts in the majority of affected fish. In addition, 2 fish had histological evidence of acute inflammation and basophilic amorphous material that could represent an exudate, potentially representing an earlier stage in the inflammatory process. While small numbers of atrophic myocytes were visible, there was little evidence of muscle necrosis, and the inflammatory process appeared to be focused predominantly in the perivertebral connective tissues and the horizontal septum. This suggests that the inflammatory reaction starts in the perivertebral tissues rather than developing as a primary myositis. However, as fibrosis is the end-stage of the inflammatory process, the initiating cause often can only be determined early in the inflammatory reaction.

If inflammation and subsequent fibrosis causes LKS in farmed Chinook salmon, determining the cause of the inflammation may aid in the development of strategies to reduce the incidence of LKS. Traumatic injury is a frequent initiator of inflammation in all species. While external trauma is unlikely to cause perivertebral inflammation, spinal curvature in Atlantic salmon has been suggested to be caused by short-term high intensity exercise (Witten et al. 2005). This 'mechanical overload' could result because salmon have been selected for large muscles. If excessive mechanical force is generated by these large muscles, this could result in injury to the connective tissue muscle tendons and their vertebral insertions. In the presently described Chinook salmon, the inflammation and fibrosis was most consistently present close to the insertion of the horizontal septum. The horizontal septum is considered to be the major transmitter of muscle force to the axial skeleton (Westneat et al. 1993). Therefore, it is possible that intense muscular activity could damage the connective tissue within, and adjacent to, the horizontal septum, resulting in the observed inflamma- tion and subsequent reparative fibrosis. The myosepta are also important in transmitting force (Gemballa et al. 2003), so that damage to the myosepta or even the myomeres themselves could cause the muscle fibrosis that was observed in some more severely affected fish. Currently, high-intensity exercise seems a plausible hypothesis for the development of the unilateral fibrosis seen in Chinook salmon with LKS.

Inflammation due to vaccination has been associated with spinal curvature in farmed Atlantic salmon (Kvellestad et al. 2000, Berg et al. 2012). In Atlantic salmon, vaccination is hypothesized to trigger a systemic autoimmune condition that causes inflammatory lesions to develop in many tissues throughout the body (Koppang et al. 2008). As part of this systemic reaction to vaccination, perivertebral fibrosis has been reported, and this perivertebral fibrosis has been suggested to be the cause of higher rates of spinal deformity observed in vaccinated fish (Haugarvoll et al. 2010). The perivertebral inflammation and fibrosis observed in Chinook with LKS is similar to the perivertebral lesion reported in vaccinated Atlantic salmon. This suggests that Chinook salmon may also develop a systemic autoimmunity or increased inflammatory condition. As salmon in New Zealand are not vaccinated, any systemic inflammatory disease is not triggered by vaccination. However, it is possible that other environmental or genetic factors could predispose these fish to mounting an excessive inflammatory reaction to a normal stimulus. A significant difference between vaccinated Atlantic salmon and the presently described Chinook salmon is the restriction of the fibrosis to the perivertebral tissues. This suggests that if a predisposition to an increased inflammatory reaction is part of the pathogenesis of LKS in Chinook salmon, the trigger for this inflammation and the subsequent inflammatory response is confined to the perivertebral tissues.

Farmed Chinook salmon receive commercial diets that have often been optimized for other salmonid species, and nutrition cannot be ruled out as a possible contributing factor to the development of LKS. In Atlantic salmon, diets containing a high proportion of vegetable oils have been suggested to promote inflammation (Gil-Martens 2010), although a clear link with spinal deformity has not been demonstrated (Gil-Martens et al. 2010). While diet could potentially influence the severity of inflammation in farmed Chinook salmon, the trigger for the inflammation in the perivertebral tissues remains unknown. Deficiency of vitamin $\mathrm{C}$ can cause spinal curvature and inflammation in the surrounding tissues in Atlantic salmon 
(Halver et al. 1969, Silverstone \& Hammell 2002). However, as the role of vitamin $\mathrm{C}$ in fish disease is well recognized and commercial diets are formulated to ensure that adequate vitamin $\mathrm{C}$ is included, this appears unlikely to be a factor in LKS development. Sub-optimal dietary phosphorus or vitamin D also influences the development of spinal curvature in Atlantic salmon by affecting bone mineralization (Fjelldal et al. 2012a,c). While evidence from the presently described fish suggests that LKS is less likely to be caused by disorders in vertebral bone development, alterations in bone mineralization can be difficult to detect in decalcified histology sections, so it remains possible that loss of bone mineral could influence LKS in farmed Chinook salmon. Deficiencies of other minerals, for example copper, influence the strength of connective tissue in other species (Tinker \& Rucker 1985). It is therefore possible that suboptimal nutrition could reduce the strength of the connective tissue in the Chinook salmon, predisposing the fish to mechanically induced trauma and subsequent fibrosis.

Other potential factors that have been associated with spinal curvature in Atlantic salmon include environmental factors such as water temperature and currents, growth rates and the age at smoltification (Silverstone \& Hammell 2002, Fjelldal et al. 2012b, Boglione et al. 2013b, Berillis 2015). While studies have not revealed an influence of growth rate or age at smoltification on the development of LKS in Chinook salmon (J. E. Symonds unpubl. data), it appears possible that other environmental factors could influence LKS development. Spinal curvature in Atlantic salmon may also be influenced by the genetics of the fish (Gjerde et al. 2005). Interestingly, genetically mediated differences in the inflammatory response of Atlantic salmon to vaccination have been detected (Drangsholt et al. 2011), suggesting that some fish could have a genetic predisposition to an increased inflammatory reaction. However, genetic analysis of Chinook salmon families has so far revealed only a low to moderate heritability for LKS in this species (M. A. Preece unpubl. data). Infectious agents have been associated with spinal curvature in other fish species (Kent et al. 2004, Sarker et al. 2015). Farmed Chinook salmon are routinely screened for infectious agents. However, if a predisposition to developing an excessive inflammatory reaction is important in the development of LKS, then it is possible that transient infection by an agent generally considered non-pathogenic could trigger an excessive inflammatory reaction that results in fibrosis and LKS. Additional molecular-based studies of Chinook salmon, especially those in the early stages of LKS, are required before an infectious agent can definitively be excluded.

Both the weight and length of fish with visible LKS were less than those of control fish. The cause of the reduced growth is uncertain, but it may be due to a reduced ability to compete for food. The reduced weight of fish with LKS at harvest, along with the downgrading of fish with LKS, demonstrates the negative economic impact of LKS in farmed Chinook salmon. This importance is increased as LKS appears to develop only in fish in the later stages of the farming cycle.

In conclusion, this is the first histological investigation of LKS in farmed Chinook salmon in New Zealand. Histology revealed that unilateral fibrosis of the perivertebral connective tissue, the horizontal septa and the myosepta was associated with LKS. The severity of fibrosis was significantly greater in fish with visible LKS than in fish that did not have visible LKS, and the severity of fibrosis was correlated to the radiographic severity of LKS. While the cause of the perivertebral fibrosis is currently unknown, measures to reduce inflammation and subsequent fibrosis may reduce the incidence of LKS in farmed Chinook salmon in New Zealand.

Acknowledgements. We acknowledge the National Institute of Water and Atmospheric Research (NIWA) and the Ministry for Primary Industries (Sustainable Farming Fund [SFF] Project 13/003: Reducing malformations in farmed King salmon). We also thank the New Zealand King Salmon (Ltd) and NIWA for technical resources enabling this study to proceed. This study involved the SFF project team, the 'Salmon Improvement Group', and we thank all members of this group for their input and advice. We also thank the New Zealand salmon farmers who provided samples from their farms for us to analyse.

\section{LITERATURE CITED}

Andrades JA, Becerra J, Fernández-Llebrez P (1996) Skeletal deformities in larval, juvenile and adult stages of cultured gilthead sea bream (Sparus aurata L.). Aquaculture 141:1-11

> Berg A, Yurtseva A, Hansen T, Lajus D, Fjelldal PG (2012) Vaccinated farmed Atlantic salmon are susceptible to spinal and skull deformities. J Appl Ichthyol 28:446-452

Berillis P (2015) Factors that can lead to the development of skeletal deformities in fishes: a review. J Fish Sci 9:17-23

Boglione C, Gavaia P, Koumoundouros G, Gisbert E, Moren M, Fontagné S, Witten PE (2013a) Skeletal anomalies in reared European fish larvae and juveniles. Part 1: normal and anomalous skeletogenic processes. Rev Aquacult 5: S99-S120

Boglione C, Gisbert E, Gavaia PE, Witten P, Moren M, Fontagné S, Koumoundouros G (2013b) Skeletal anomalies in reared European fish larvae and juveniles. Part 2: 
main typologies, occurrences and causative factors. Rev Aquacult 5:S121-S167

Chatain B (1994) Abnormal swimbladder development and lordosis in sea bass (Dicentrarchus labrax) and sea bream (Sparus auratus). Aquaculture 119:371-379

Cobcroft JM, Battaglene SC (2013) Skeletal malformations in Australian marine finfish hatcheries. Aquaculture 396-399:51-58

> Drangsholt TMK, Gjerde B, Ødegård J, Fridell F, Bentsen HB (2011) Quantitative genetics of vaccine-induced side effects in farmed Atlantic salmon (Salmo salar). Aquaculture 318:316-324

Fjelldal PG, Hansen TJ, Berg AE (2007) A radiological study on the development of vertebral deformities in cultured Atlantic salmon (Salmo salar L.). Aquaculture 273:721-728

Fjelldal PG, Hansen T, Albrektsen S (2012a) Inadequate phosphorus nutrition in juvenile Atlantic salmon has a negative effect on long-term bone health. Aquaculture 334-337:117-123

Fjelldal PG, Hansen T, Breck O, Ørnsrud R and others (2012b) Vertebral deformities in farmed Atlantic salmon (Salmo salar L.) - etiology and pathology. J Appl Ichthyol 28:433-440

Fjelldal PG, Lock EJ, Hansen T, Waagbø R and others (2012c) Continuous light induces bone resorption and affects vertebral morphology in Atlantic salmon (Salmo salar L.) fed a phosphorous [sic] deficient diet. Aquacult Nutr 18:610-619

Gemballa S, Ebmeyer L, Hagen K, Hannich T and others (2003) Evolutionary transformations of myoseptal tendons in gnathostomes. Proc R Soc Lond B Biol Sci 270: 1229-1235

Gil-Martens L (2010) Inflammation as a potential risk factor for spinal deformities in farmed Atlantic salmon (Salmo salar L.). J Appl Ichthyol 26:350-354

Gil-Martens L, Lock EJ, Fjelldal PG, Wargelius A and others (2010) Dietary fatty acids and inflammation in the vertebral column of Atlantic salmon, Salmo salar L., smolts: a possible link to spinal deformities. J Fish Dis 33:957-972

Gjerde B, Pante MJR, Baeverfjord G (2005) Genetic variation for a vertebral deformity in Atlantic salmon (Salmo salar). Aquaculture 244:77-87

Gorman KF, Pohl K, Ali F, Bandwait K, Breden F (2012) Model teleosts for the study of idiopathic-type spinal curvatures: potential biomedical applications. J Appl Ichthyol 28:353-359

Halver JE, Ashley LM, Smith RR (1969) Ascorbic acid requirements of coho salmon and rainbow trout. Trans Am Fish Soc 98:762-771

Hansen T, Fjelldal PG, Yurtseva A, Berg A (2010) A possible relation between growth and number of deformed vertebrae in Atlantic salmon (Salmo salar L.). J Appl Ichthyol $26: 355-359$

Editorial responsibility: Thomas Lang,

Cuxhaven, Germany
Haugarvoll E, Bjerkas I, Szabo NJ, Satoh M, Koppang EO (2010) Manifestations of systemic autoimmunity in vaccinated salmon. Vaccine 28:4961-4969

Kacem A, Meunier FJ, Baglinière JL (1998) A quantitative study of morphological and histological changes in the skeleton of Salmo salar during its anadromous migration. J Fish Biol 53:1096-1109

Kent ML, Watral VG, Whipps CM, Cunningham ME and others (2004) A digenean metacercaria (Apophallus sp.) and a myxozoan (Myxobolus sp.) associated with vertebral deformities in cyprinid fishes from the Willamette River, Oregon. J Aquat Anim Health 16:116-129

Koppang EO, Bjerkås I, Haugarvoll E, Chan EK and others (2008) Vaccination-induced systemic autoimmunity in farmed Atlantic salmon. J Immunol 181: 4807-4814

Kumar V, Abbas AK, Fausto N, Aster JC (2010) Tissue renewal, regeneration, and repair. In: Kumar V, Abbas AK, Fausto N, Aster JC (eds) Robins and Cotran pathologic basis of disease. Elsevier Saunders, Philadelphia, PA, p 87-118

- Kvellestad A, Høie S, Thorud K, Tørud B, Lyngøy A (2000) Platyspondyly and shortness of vertebral column in farmed Atlantic salmon Salmo salar in Norwaydescription and interpretation of pathologic changes. Dis Aquat Org 39:97-108

Sarker S, Kallert DM, Hedrick RP, El-Matbouli M (2015) Whirling disease revisited: pathogenesis, parasite biology and disease intervention. Dis Aquat Org 114: 155-175

Silverstone AM, Hammell L (2002) Spinal deformities in farmed Atlantic salmon. Can Vet J 43:782-784

Tinker D, Rucker RB (1985) Role of selected nutrients in synthesis, accumulation, and chemical modification of connective tissue proteins. Physiol Rev 65:607-657

Westneat MW, Hoese W, Pell CA, Wainwright SA (1993) The horizontal septum: mechanisms of force transfer in locomotion of scombrid fishes (Scombridae, Perciformes). J Morphol 217:183-204

> Witten PE, Gil-Martens L, Hall BK, Huysseune A, Obach A (2005) Compressed vertebrae in Atlantic salmon Salmo salar: evidence for metaplastic chondrogenesis as a skeletogenic response late in ontogeny. Dis Aquat Org 64:237-246

> Witten PE, Obach A, Huysseune A, Baeverfjord G (2006) Vertebrae fusion in Atlantic salmon (Salmo salar): development, aggravation and pathways of containment. Aquaculture 258:164-172

Witten PE, Gil-Martens L, Huysseune A, Takle H, Hjelde K (2009) Towards a classification and an understanding of developmental relationships of vertebral body malformations in Atlantic salmon (Salmo salar L.). Aquaculture 295:6-14

Submitted: April 28, 2016; Accepted: August 17, 2016

Proofs received from author(s): October 14, 2016 